\title{
Composition of Eukaryotic and Prokaryotic rRNA Gene Phylotypes in Guts of Adults and Fingerlings of Mugil cephalus, Inhabiting an Egyptian Mediterranean Estuary
}

\author{
Hosam E Elsaied ${ }^{1 *}$, Hany T Abu Taleb1 ${ }^{1}$, Mai A Wassel ${ }^{1}$ and Mohamed Abdel-Salam Rashed ${ }^{2}$ \\ ${ }^{1}$ Genetics and Genetic Engineering Research Group, National Institute of Oceanography and Fisheries, NIOF, Cairo, Egypt \\ ${ }^{2}$ Department of Genetics, Faculty of Agriculture, Ain Shams University, Shubra El-Khima, Qalyobeya, Egypt
}

\begin{abstract}
To understand the contribution of gut microflora to the feeding and health of Mugil cephalus in a Mediterranean estuary, we have explored and evaluated the diversity of rRNA genes in gut contents of both of adults and fingerlings. Bulk DNAs were extracted from the fish guts, followed by PCR, cloning and sequencing of eukaryote 18S rRNA gene; bacterial and archaeal 16S rRNA genes. Rarefaction analyses recorded 11, 18 and 13 phylotype groups of rRNA genes for eukaryotes, bacteria and archaea, respectively, in the adult guts. The fingerling guts contained 6 and 11 phylotype groups of rRNA genes for eukartyotes and bacteria, respectively, while lacked archaea. Adult and fingerling guts were dominated by zooplankton-like 18S rRNA gene phylotypes, belonging to those of rotifers, genus Brachionus and copepods, genus Apocyclops. Both of diatoms, genus Cyclotella- and fish-like rRNA gene phylotypes were recorded only in adult guts. Phylotypes, which belonged to uncultured proteobacteria and cyanobacteria, covered most of the bacterial 16S rRNA gene composition of adult guts. Bacteroidetes-like phylotypes characterized the fingerling guts. The study showed the first record of uncultured thaumarchaeote-like 16S rRNA genes in the fish guts, opening a window for exploring thaumarchaeote biological significances in fish metabolism. The fish guts represented a reservoir for geographic distant species and reflected the plankton ecosystem variability at the studied estuary. The pollution in the estuary could shape a fraction of the fish gut microbiota. To our knowledge, this work presented the first complete profile of rRNA gene diversities for all known microbiome domains in fish guts.
\end{abstract}

Keywords: Mugil cephalus; Gut contents; rRNA gene diversities; Mediterranean estuary

\section{Introduction}

Mullets, family Mugilidae, are catadromous worldwide fishes. They inhabit coastal temperate and tropical waters. The flathead grey mullet, Mugil cephalus, is euryhaline species, meaning that the fish can acclimate to different levels of salinity. Hence, M. cephalus is a mainly diurnal coastal species that often occurs in estuaries and rivers for feeding.

The fish gut microbiota contribute to the nutrition, growth, reproduction, overall population dynamics and vulnerability of the host fish to disease; therefore, this microbial community is highly relevant for aquaculture practice [1]. The composition of the intestinal microbial community is determined in part by fish dietary preferences and fish life stage [2]. For migratory fishes, such as mullet, successful exploitation of variable habitat, such as estuaries, may affect and be affected by the composition of the intestinal microbiome [3]. The microscopic analyses of the gut of adult $M$. cephalus have revealed the existence of Chlorophyceae, Myxophyceae, Bacillariophyceae, dinoflagellates, copepods and polycheatae worms along with sand and mud [4,5]. High level of benthic diatoms has been recorded in the gut content of M. cephalus from Tamiahua lagoon, México [6]. Other microflora have been studied in the gut contents of $M$. cephalus at Kayamkulam estuary, India [7]. The gut contents of $M$. cephalus juveniles varied, where the Bacillariophyceae and Myxophyceae were prominent [5]. On the other hand, M. barbatus, red mullet, larvae probably depend on energy derived from the microbial food web, via their feeding on cladocera at northwest Mediterranean [8].

For historical reasons, much of the information available on the intestinal bacteria of fish is based on the use of conventional culturedependent methods. This has consisted of sampling of gut material and spreading gut homogenates on selective or general purpose agar, followed by incubation, colony counting and subsequent identification, typically, by phenotypic / biochemical tests or, during the last decade, 16S rRNA gene sequencing [9]. As is often the case with microbial communities from environmental samples, the gut microbiota of fish has been reported to be of low cultivability, where cultivability using general purpose culture media has been reported to represent $<0.1 \%$ of the total microbial community in the gastrointestinal tract of some fish species [10]. A wide range of molecular ecology techniques are available based on the sequence variability of the rRNA genes, and over the last 10-12 years such approaches have become more commonly used to investigate the gut bacteria of fish species. The molecularbased approaches used have depended on the aim of the studies. Clone libraries have been used to identify the uncultured bacterial composition in the fish guts [11-13]. Thus, molecular methods have provided faster results, novel and high-resolution insights into the structure and diversity of bacterial communities within the digestive tracts of freshwater and marine fishes [14-16].

Previous studies have focused on microscopic identification of microbial eukaryotes in fish guts, a method, which lacks accuracy in discrimination of species, due to partial or complete digestion of the ingested prey. On the other hand, the applications of rRNA gene analyses, in studying the diversity of fish gut prokaryotes, have focused on bacteria, leaving a gap for exploring and evaluation of uncultured archaeal communities.

In this study, we provided a complete profile for ssrRNA gene phylotypes of eukaryotes, bacteria and archaea, in the guts of adult

*Corresponding author: Hosam Easa Elsaied, Genetics and Genetic Engineering Research Group, National Institute of Oceanography and Fisheries, NIOF, Cairo, Egypt, Tel: +201010908086; E-mail: hosameasa@yahoo.com

Received March 07, 2016; Accepted March 28, 2016; Published April 06, 2016

Citation: Elsaied HE, Taleb HTA, Wassel MA, Rashed MAS (2016) Composition of Eukaryotic and Prokaryotic Rrna Gene Phylotypes uin Guts of Adults and Fingerlings of Mugil cephalus, Inhabiting an Egyptian Mediterranean Estuary. J Phylogen Evolution Biol 4: 164. doi:10.4172/2329-9002.1000164

Copyright: ( 2016 Elsaied HE, et al. This is an open-access article distributed under the terms of the Creative Commons Attribution License, which permits unrestricted use, distribution, and reproduction in any medium, provided the original author and source are credited. 
Citation: Elsaied HE, Taleb HTA, Wassel MA, Rashed MAS (2016) Composition of Eukaryotic and Prokaryotic Rrna Gene Phylotypes uin Guts of Adults and Fingerlings of Mugil cephalus, Inhabiting an Egyptian Mediterranean Estuary. J Phylogen Evolution Biol 4: 164. doi:10.4172/23299002.1000164

Page 2 of 9

and fingerling stages of $M$. cephalus in a Mediterranean estuary. The approach of culture-independent PCR / cloning and sequencing, for both of eukaryotic $18 \mathrm{~S}$ rRNA gene and bacterial and archaeal $16 \mathrm{~S}$ rRNA genes, was used to construct phylograms for the studied gut microflora.

\section{Materials and Methods}

\section{Sampling}

M. cephalus specimens were collected from the estuary, Ashtum El-Gamil, which is a natural reserved estuary and constitutes the main gate of freshwater Manzallah Lake to the Egyptian eastern coast of Mediterranean Sea, 31 $18^{\prime} 15.39^{\prime \prime N}$; 32 $10^{\prime} 13.76^{\prime \prime}$. The estuary is shallow water, average depth of $2 \mathrm{~m}$, and covers an area of $35 \mathrm{Km}^{2}$, with water salinity, which varies between $30 \%$, at the side of the sea, to $5 \%$, at the lake side. This salinity variation may favor the biodiversity of plankton species, the main food components for mullets, which come from the oligotrophic Sea.

M. cephalus, adult and fingerling specimens, 100 individuals from each life stage, were collected between mid of spring and late of autumn, the time of abundance of mullets in the estuary. The adults had an average total length of $32 \mathrm{~cm}$, weight of $1 \mathrm{~kg}$ and age of 2-3 years. The sizes of fingerlings were ranged between 10 and $12 \mathrm{~mm}$ in total length, and may correspond to ages of 29 to 40 days after hatching.

The adult specimens were dissected, using sterile tools, and whole guts were removed, washed carefully using sterile water and stored in ethanol at $4^{\circ} \mathrm{C}$. The fingerlings, whole specimens, were fixed in ethanol and kept at $4^{\circ} \mathrm{C}$. The guts were evacuated in TE-buffer, Tris- $\mathrm{HCl}, 10$ $\mathrm{mM}$, EDTA, $1 \mathrm{mM}$, pH 8.

\section{Molecular analyses}

Metagenomic DNAs were extracted from bulk gut contents of each of the collected fish life forms, adult or fingerling, according to [17], with modifications. The gut contents were lysed in a mixture of $5 \mathrm{M}$ guanidine thiocyanate and $10 \%$ of SDS at $70^{\circ} \mathrm{C}$ for $25 \mathrm{~min}$, with vigorous shake. The DNA was purified from the lysate, using high pure PCR template preparation kit, Catalog no. 11796828001, Roche, Germany. The purified DNA was run on $0.9 \%$ agarose gel electrophoresis, followed by staining with ethidium bromide and UV visualization.

PCR amplification of the 18S rRNA gene was done, using the primers, EuK63F, 5'-ACG CTT GTC TCA AAG ATT A-3' and Eukarya-1818R, 5'-ACG GAA ACC TTG TTA CGA-3' [18]. The primers, EuBac-27F, 5'-AGA GTT TGA TCC TGG CTC AG-3' and EuBac-1492R, 5'-GGT TAC CTT GTT ACG ACT T-3' [19] were used to amplify the bacterial $16 \mathrm{~S}$ rRNA gene from the extracted DNAs. Archaeal 16S rRNA gene was amplified, using the primers, Arch-21F, 5'-TTCCGGTTGATCCYGCCGGA-3' and Arch-958R, 5'-YCCGGCGTTGAMTCCAATT-3' [20]. PCR mixture, $50 \mu \mathrm{l}$, contained 10X Ex Taq buffer II $\left(\mathrm{Mg}^{2+}\right.$ plus), $0.2 \mu \mathrm{M}$ primer, $400 \mu \mathrm{M}$ dNTP each, 2.25 U Takara Ex Taq Polymerase (Takara, Japan) and 5-30 ng DNA template. PCR was performed with an initial denaturation step of $3 \mathrm{~min}$ at $95^{\circ} \mathrm{C}$. The PCR reaction continued with 30 cycles of 1 min at $95^{\circ} \mathrm{C}, 40 \mathrm{sec}$, desirable annealing temperatures, increasing $0.5^{\circ} \mathrm{C}$ every 10 cycles, and $1 \mathrm{~min}$ extension at $72^{\circ} \mathrm{C}$. The 30 thermal cycles were followed by a final extension of $10 \mathrm{~min}$ at $72^{\circ} \mathrm{C}$, to allow $3^{\prime}$-A overhangs for the amplified PCR product to facilitate TA-cloning.

Cloning was done into TOP10 Escherichia coli, using a TOPO XL PCR-cloning kit, according to the manufacturer's instructions (Catalog no. K4750-20, Invitrogen Life Technologies, Carlsbad, CA, USA). Only cells containing XL-TOPO vector with the insert were competent to grow with kanamycin. Plasmids were extracted from the positive colonies and screened directly by sequencing, using the vector T7 primers and the 96-capillary 3730xl DNA analyzer (Applied Biosystems, Foster City, CA, USA).

Clone sequences were analyzed by FASTA screening to determine their similarity to known sequences in the DNA database (http:// ddbj. nig.ac.jp). The recovered sequences were aligned using Clustal Omega software (http://www.ebi.ac.uk/Tools/msa/clustalo/). Grouping of sequences into phylotypes was carried out, based on genetic distances, using the MOTHUR software package [21], where the sequences that had $>97 \%$ nucleotide identity, over the region compared, were collected into a single phylotype group (Tables 1 and 2).

Rarefaction analyses, in the MOTHUR software package, were carried out to visualize the extent to which the richness of the rRNA gene phylotypes was represented in the gut content samples.

Phylogenetic trees were constructed through two bioinformatics processes. In the first process, the nucleotide sequences of the recovered rRNA gene phylotypes and their homologues sequences, from the DNA database, were aligned, using the online program "Clustal Omega". In the second process, the aligned sequences were submitted to the MEGA software, V. 6.0.6, http://www.megasoftware.net/, for drawing the phylogenetic trees. Consensus phylogenetic trees were constructed by applying the three algorithms, maximum parsimony, maximum likelihood, and neighbor joining, in the same MEGA software. The current rRNA gene sequences were registered at DNA database under accession numbers listed in Tables 1 and 2.

\section{Results and Discussion}

\section{Capacity of eukaryotic and prokaryotic rRNA gene phylotypes in the gut contents of adults and fingerlings}

PCR amplifications could detect eukaryotic 18S rRNA gene, and bacterial 16S rRNA gene, with amplicon sizes $\sim 1800 \mathrm{bp}$, and $\sim 1500 \mathrm{bp}$, respectively, in the gut contents of both adults and fingerlings. On the other hand, the current archaeal primers could amplify the archaeal $16 \mathrm{~S}$ rRNA gene from gut contents of only adults. Generally, archaea have been recorded in the guts of adult fishes, as natural fermenters of indigested food remnants, while fingerlings have incomplete gut, and consequently, may lack the favorite conditions for growth of archaea [22]. Other possibility for negative detection of archaea in fingerling guts may refer to the efficiency of the current primers. However, those primers could amplify archaeal $16 \mathrm{~S}$ rRNA gene, in the form of different phylotypes, from gut contents of the adults (Table 1). Archaeal 16S rRNA gene has not been detected in the guts of zebraperch [11].

The eukaryote $18 \mathrm{~S}$ rRNA gene phylotype groups 2 and 7, beside the archaeal 16S rRNA gene phylotype group 5, contained 4 to 5 phylotypes within each group, sharing nucleotide identities, 97\% - 99\% (Table 1). These sequence variations between recorded phylotypes within the single group (Tables 1 and 2) may indicate that the possibility of bias in PCR amplifications was minimized. This is because the PCR was tested on the bulk DNA extracted from gut contents by a) increasing the annealing temperature of $0.5^{\circ} \mathrm{C}$ every 10 PCR cycles, and b) doing PCR using number of cycles ranged from 26 to 30 cycles, and the amplicons were combined for cloning [23]. Hence, the PCR could screen as much as possible of the actual composition of rRNA gene variants in the fish gut contents, as presented in this work.

Previous studies have focused on counting of macroscopic eukaryotic species in the gut of $M$. cephalus $[2,5,24]$. Compared with other studies, the present molecular study could detect eukaryotic 
Citation: Elsaied HE, Taleb HTA, Wassel MA, Rashed MAS (2016) Composition of Eukaryotic and Prokaryotic Rrna Gene Phylotypes uin Guts of Adults and Fingerlings of Mugil cephalus, Inhabiting an Egyptian Mediterranean Estuary. J Phylogen Evolution Biol 4: 164. doi:10.4172/23299002.1000164

Page 3 of 9

\begin{tabular}{|c|c|c|c|c|c|c|c|c|}
\hline $\begin{array}{l}\text { Eukaryote } \\
\text { groups }\end{array}$ & Phylotypes & Acc. numbers & $\begin{array}{c}\text { Bacteria } \\
\text { groups }\end{array}$ & Phylotypes & Acc. numbers & $\begin{array}{c}\text { Archaea } \\
\text { groups }\end{array}$ & Phylotypes & Acc. numbers \\
\hline \multirow[t]{2}{*}{ Group 1} & 1-EukAdul & LC121830 & Group 1 & 1-BacAdul & LC121858 & Group 1 & 1-ArcAdul & LC121889 \\
\hline & 2-EukAdul & LC121831 & & & & & & \\
\hline \multirow[t]{4}{*}{ Group 2} & 3-EukAdul & LC121832 & Group 2 & 2-BacAdul & LC121859 & Group2 & 2-ArcAdul & LC121890 \\
\hline & 4-EukAdul & LC121833 & & & & & & \\
\hline & 6-EukAdul & LC121835 & & & & & & \\
\hline & 12-EukAdul & LC121841 & & & & & & \\
\hline Group 3 & 5-EukAdul & LC121834 & Group 3 & 3-BacAdul & LC121860 & Group 3 & 3-ArcAdul & LC121891 \\
\hline \multirow[t]{2}{*}{ Group 4} & 7-EukAdul & LC121836 & Group 4 & 4-BacAdul & LC121861 & Group 4 & 4-ArcAdul & LC121892 \\
\hline & 8-EukAdul & LC121837 & & & & & & \\
\hline \multirow[t]{5}{*}{ Group 5} & 9-EukAdul & LC121838 & Group 5 & 5-BacAdul & LC121862 & Group 5 & 5-ArcAdul & LC121893 \\
\hline & 11-EukAdul & LC121840 & & & & & 8-ArcAdul & LC121896 \\
\hline & & & & & & & 12-ArcAdul & LC121900 \\
\hline & & & & & & & 14-ArcAdul & LC121902 \\
\hline & & & & & & & 15-ArcAdul & LC121903 \\
\hline Group 6 & 10-EukAdul & LC121839 & Group 6 & 6-BacAdul & LC121863 & Group 6 & 6-ArcAdul & LC121894 \\
\hline \multirow[t]{4}{*}{ Group 7} & 13-EukAdul & LC121842 & Group 7 & 7-BacAdul & LC121864 & Group 7 & 7-ArcAdul & LC121895 \\
\hline & 14-EukAdul & LC121843 & & & & & & \\
\hline & 15-EukAdul & LC121844 & & & & & & \\
\hline & 17-EukAdul & LC121846 & & & & & & \\
\hline Group 8 & 16-EukAdul & LC121845 & Group 8 & 8-BacAdul & LC121865 & Group 8 & 9-ArcAdul & LC121897 \\
\hline Group 9 & 18-EukAdul & LC121847 & Group 9 & 9-BacAdul & LC121866 & Group 9 & 10-ArcAdul & LC121898 \\
\hline \multirow[t]{2}{*}{ Group 10} & 19-EukAdul & LC121848 & Group 10 & 10-BacAdul & LC121867 & Group 10 & 11-ArcAdul & LC121899 \\
\hline & 20-EukAdul & LC121849 & & & & & & \\
\hline \multirow[t]{8}{*}{ Group 11} & 21-EukAdul & LC121850 & Group 11 & 11-BacAdul & LC121868 & Group 11 & 13-ArcAdul & LC121901 \\
\hline & & & Group 12 & 12-BacAdul & LC121869 & Group 12 & 16-ArcAdul & LC121904 \\
\hline & & & Group 13 & 13-BacAdul & LC121870 & Group 13 & 17-ArcAdul & LC121905 \\
\hline & & & Group 14 & 14-BacAdul & LC121871 & & & \\
\hline & & & Group 15 & 15-BacAdul & LC121872 & & & \\
\hline & & & Group 16 & 16-BacAdul & LC121873 & & & \\
\hline & & & Group 17 & 17-BacAdul & LC121874 & & & \\
\hline & & & Group 18 & 18-BacAdul & LC121875 & & & \\
\hline
\end{tabular}

Table 1: Eukaryotic and prokaryotic rRNA gene phylotype groups recorded in the gut contents of adults.

\begin{tabular}{|c|c|c|c|c|c|}
\hline Eukaryote & phylotypes & Acc. & Bacteria & Phylotypes & Acc. \\
groups & & numbers & groups & & numbers \\
\hline Group 1 & 1-EukFinL & LC121851 & Group 1 & 1-BacFinL & LC121876 \\
\hline & & & & 2-BacFinL & LC121877 \\
\hline & & & & 11-BacFinL & LC121886 \\
\hline Group 2 & 2-EukFinL & LC121852 & Group 2 & 3-BacFinL & LC121878 \\
\hline Group 3 & 3-EukFinL & LC121853 & Group 3 & 4-BacFinL & LC121879 \\
\hline & 4-EukFinL & LC121854 & & & \\
\hline Group 4 & 5-EukFinL & LC121855 & Group 4 & 5-BacFinL & LC121880 \\
\hline Group 5 & 6-EukFinL & LC121856 & Group 5 & 6-BacFinL & LC121881 \\
\hline Group 6 & 7-EukFinL & LC121857 & Group 6 & 7-BacFinL & LC121882 \\
\hline & & & Group 7 & 8-BacFinL & LC121883 \\
\hline & & & Group 8 & 9-BacFinL & LC121884 \\
\hline & & & Group 9 & 10-BacFinL & LC121885 \\
\hline & & & Group 10 & 12-BacFinL & LC121887 \\
\hline & & & Group 11 & 13-BacFinL & LC121888 \\
\hline
\end{tabular}

Table 2: Eukaryotic and prokaryotic rRNA gene phylotype groups recorded in the gut contents of fingerlings.

phylotypes in the level of strains, representing by phylotypes sharing $18 \mathrm{~S}$ rRNA gene nucleotide identities $>97 \%$, which cannot be detected by macroscopic analyses.

The saturation of rarefaction curves indicated that the sampled sequences could cover the actual composition of rRNA gene phylotypes in the gut contents of both of adults and fingerlings (Figure
1). The rarefaction analyses recorded 11 and 6 phylotype groups of eukaryote $18 \mathrm{~S}$ rRNA gene in the gut contents of adults and fingerlings, respectively (Figures $1 \mathrm{a}$ and $1 \mathrm{~b}$ ). The bacterial $16 \mathrm{~S}$ rRNA gene pool was represented by 18 and 11 phylotype groups in the gut contents of adults and fingerlings, respectively (Figures $1 \mathrm{c}$ and $1 \mathrm{~d}$ ). Fluctuation in bacterial composition, between three to five species, has been recorded in the alimentary tract of grey mullets living in freshwater and marine, respectively [25]. Eight bacterial species have been recorded in the intestinal tract of $M$. cephalus, west coast of India [26]. However, variation between current gut bacterial composition and those of previous studies may depend on sampling environment and the method of gut examination. However, the current work represented the first examination of bacterial composition in mullet guts based on culture-independent $16 \mathrm{~S}$ rRNA gene analyses. Generally, compositions of bacterial $16 \mathrm{~S}$ rRNA gene phylotypes have been varying in the gut contents of 12 bony fishes and 3 sharks, ranging from 7 to 60 phylotypes in each fish species [27].

Archaeal $16 \mathrm{~S}$ rRNA gene was represented by 13 phylotype groups in the adult gut contents (Figure 1e). Generally, studies on diversity of archaea in fish guts are very limited, comparing with higher animals. The current archaeal 16S rRNA gene composition represented the largest diversity of archaeal phylotypes recorded in fish guts. Due to knowledge limitation, additional phylogenetic surveys must be done to explore the diversity of uncultured archaea in fish guts. 
Citation: Elsaied HE, Taleb HTA, Wassel MA, Rashed MAS (2016) Composition of Eukaryotic and Prokaryotic Rrna Gene Phylotypes uin Guts of Adults and Fingerlings of Mugil cephalus, Inhabiting an Egyptian Mediterranean Estuary. J Phylogen Evolution Biol 4: 164. doi:10.4172/23299002.1000164

(a)

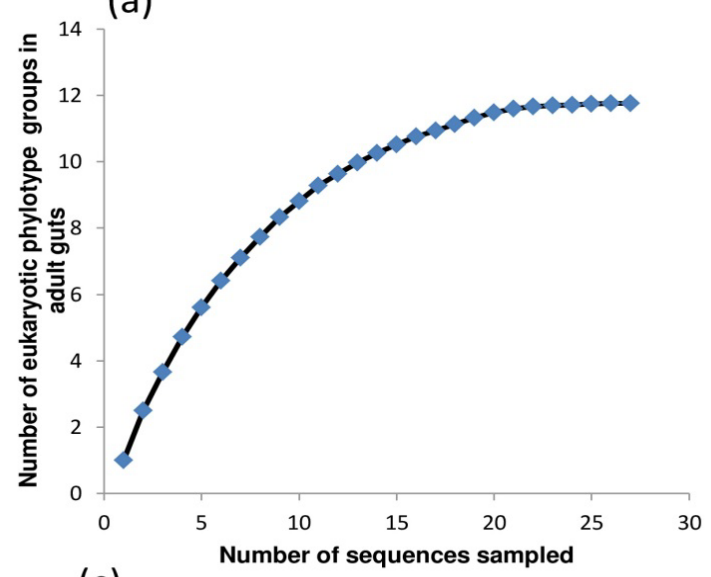

(c)

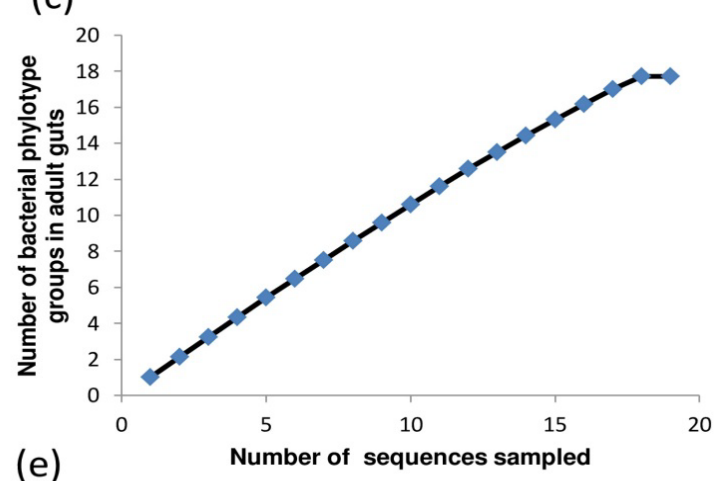

(e)

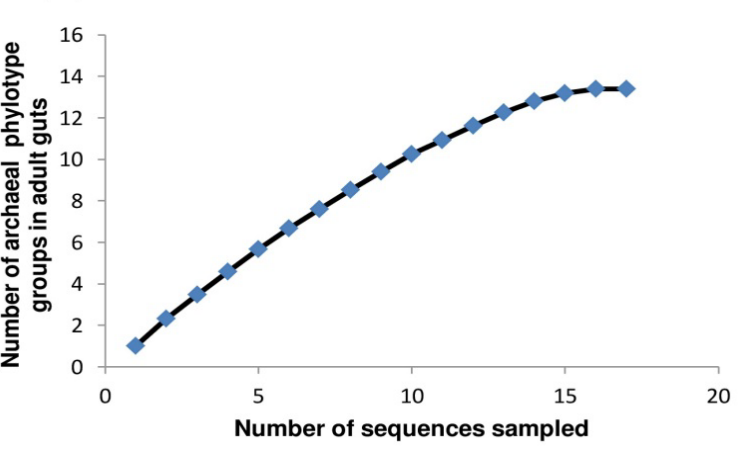

(b)
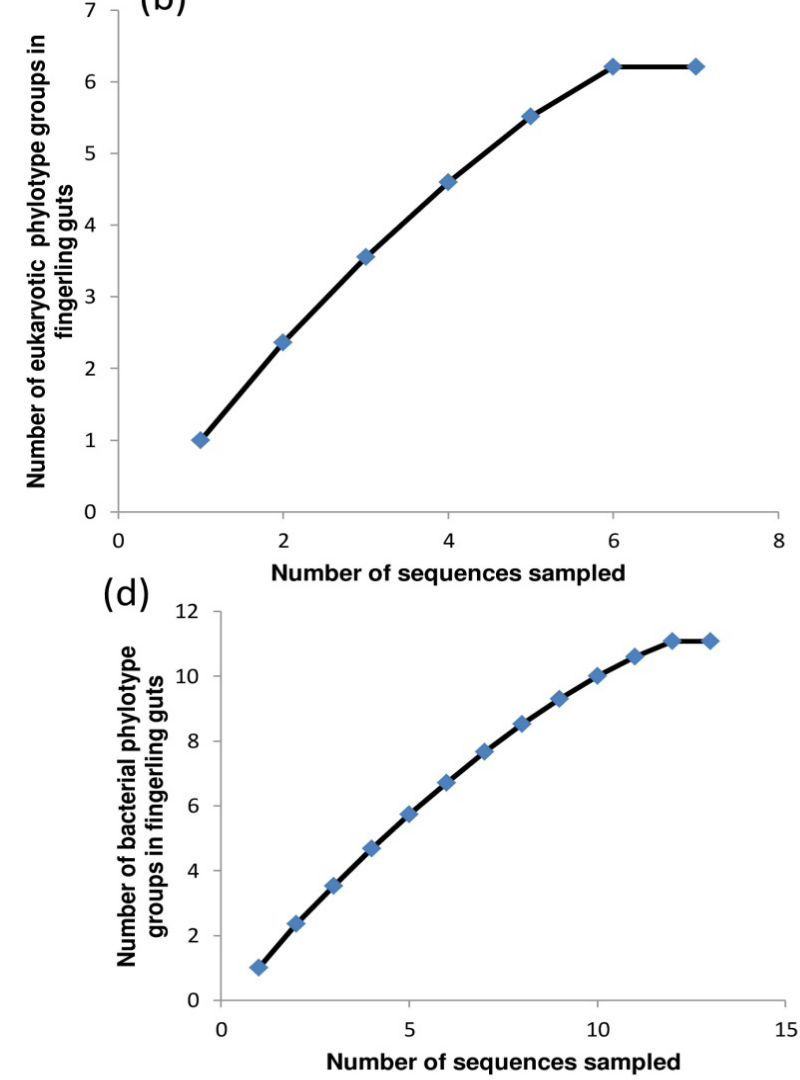

Figure 1: Rarefaction curves for the expected number of rRNA gene phylotype groups (a) eukaryote 18S rRNA gene phylotype groups in adult guts. (b) Eukaryote 18S rRNA gene phylotype groups in fingerling guts. (c) Bacterial 16S rRNA gene phylotype groups in adult guts. (d) Bacterial 16S rRNA gene phylotype groups in fingerling guts. (e) Archaeal 16S rRNA gene phylotype groups in adult guts.

Brachionus and Apocyclops phylotypes represented the dominant eukaryotes in the guts of both adults and fingerlings, while the diatom Cyclotella and fish-like phylotypes were recorded in the guts of adults

The eukaryotic $18 \mathrm{~S}$ rRNA gene phylotypes were distributed in the branches of 6 phylogenetic taxa (Figure 2). We have recorded 7 and 4 phylotypes, in gut contents of adults and fingerlings, respectively, forming monophyletic and paraphyletic clades with species Brachionus calyciflorus and B. plicatilis (Figure 2) [28,29]. The cluster of the genus Apocyclops harbored three phylotypes, from adult gut contents and a single phylotype from those of fingerlings (Figure 2). Copepods have represented $10.24 \%$ of natural total diet components of $M$. cephalus in cross river estuary, Nigeria [2]. Other phylotypes, 1-EukFinL, 5-EukAdul, 6-EukAdul, a cluster consisting of four phylotypes, 1-, 2-, 3-EukAdul, and 3-EukFinL; beside the phylotypes 5-EukFinL,
7-EukAdul, and 8-EukAdul, formed unique phylogenetic lineages in the branches of the genera Brachionus and Apocyclops, respectively (Figure 2). DNA sequencing studies have revealed B. plicatilis to be a cryptic species complex, comprising approximately of 15 known separate species, each of which has been diverged for several million years [30]. However, these current unique phylotypes may represent new discovered species.

A unique cluster was formed by the phylotypes 19-, 20- and 21-EukAdul in the branch of fishes and showed an average nucleotide identity percentage of $97.77 \%$ with the genera Sarpa, Epinephelus and Auxis. The similarity between current phylotypes and those of common Mediterranean fishes may implicate that larvae and fries of these fishes are target preys for the studied M. cephalus. However, fish larvae have been recorded in the guts of stripped mullets [2,24,31]. These observations may indicate the abundance of zooplankton-like 
Citation: Elsaied HE, Taleb HTA, Wassel MA, Rashed MAS (2016) Composition of Eukaryotic and Prokaryotic Rrna Gene Phylotypes uin Guts of Adults and Fingerlings of Mugil cephalus, Inhabiting an Egyptian Mediterranean Estuary. J Phylogen Evolution Biol 4: 164. doi:10.4172/23299002.1000164

Page 5 of 9

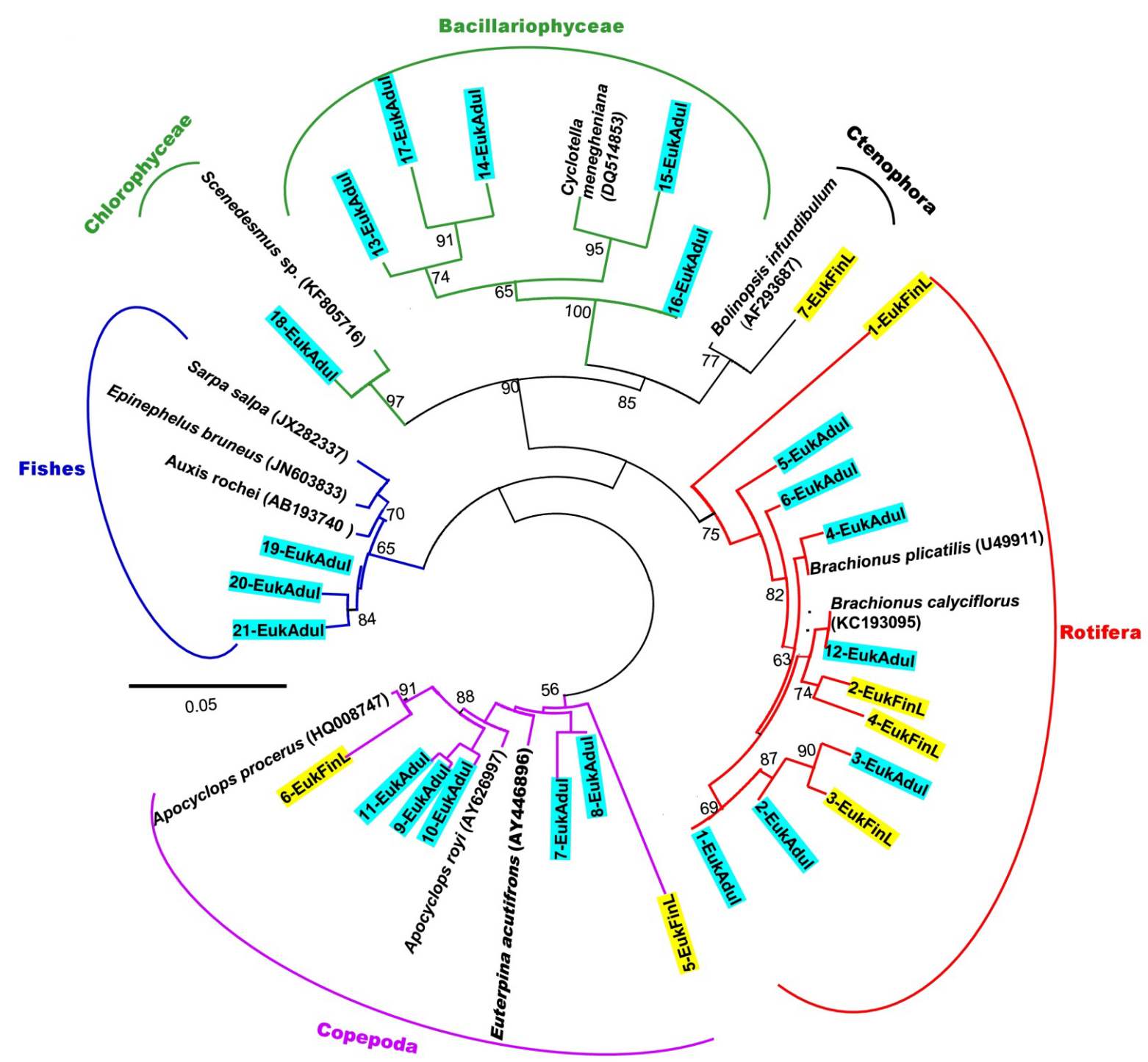

Figure 2: A consensus phylogenetic tree based on 18S rRNA gene sequences of current eukaryote phylotypes in adult and fingerling guts; beside their corresponding sequences from database. Bootstrap values, more than $50 \%$, of compared algorithms, are indicated at the branch roots. The bar represents 0.05 changes per nucleotide. Accession numbers of database extracted sequences are in brackets.

phylotypes in the gut contents of adults and fingerlings, an implication of occurrence of zooplanktivorus $M$. cephalus, as an opportunistic feeder. This concept was supported by the shifting of $M$. cephalus and Liza aurata, to zooplanktivorus, depending on abundance of zooplankton, in Spanish Mediterranean lakes [32].

Adult gut contents contained 6 phylotypes in the branch of algae, 5 phylotypes in the phylogenetic cluster of Cyclotella menegheniana, Bacillariophyceae, and a single phylotype, which formed a monophyletic clade with Scenedesmus sp., Chlorophyceae (Figure 2) [33]. Bacillariophyceae and copepod species have been recorded in the guts of adults and juveniles of $M$. cephalus at Indian estuaries, implicating favorable global food targets of mullets [5,7]. A strict congruence of nuclear rDNA has revealed the presence of eight genetically distinct lineages of C. meneghiniana [34]. On the other hand, there are 74 taxonomically accepted species of Scenedesmus [35]. The current phylotypes in the cluster of Cyclotella had an average nucleotide identity percentage of $94.5 \%$ with C. meneghiniana, implicating new phylogenetic species, eaten by mullets. On the other hand, empty stomachs have been recorded in M. cephalus at specific periods, Kayamkulam estuary, India [7].

Cyanobacteria- and proteobacteria-like phylotypes dominated in the gut contents of adults, while fingerling guts were characterized by the dominance of phylotypes in the phylum of Bacteroidetes

The bacterial 16S rRNA gene phylotypes were located in the branches of 12 phylogenetic taxa (Figure 3). Some of these taxa were represented by phylotypes in the gut contents of both adults and fingerlings, while others were specific to guts of each of fish life stages. Four phylotypes from adult gut contents and a single phylotype from those of fingerlings were distributed in the cluster of uncultured cyanobacteria (Figure 3). The abundance of cyanobacteria, observed here and in other fish guts, was possibly supported by their role as fish's major food source [13]. Of the adult gut content representative sequences, proteobacteria-like phylotypes were abundant (Figure 3). Four phylotypes were located in the branch of gammaproteobacteria 
Citation: Elsaied HE, Taleb HTA, Wassel MA, Rashed MAS (2016) Composition of Eukaryotic and Prokaryotic Rrna Gene Phylotypes uin Guts of Adults and Fingerlings of Mugil cephalus, Inhabiting an Egyptian Mediterranean Estuary. J Phylogen Evolution Biol 4: 164. doi:10.4172/23299002.1000164

Page 6 of 9

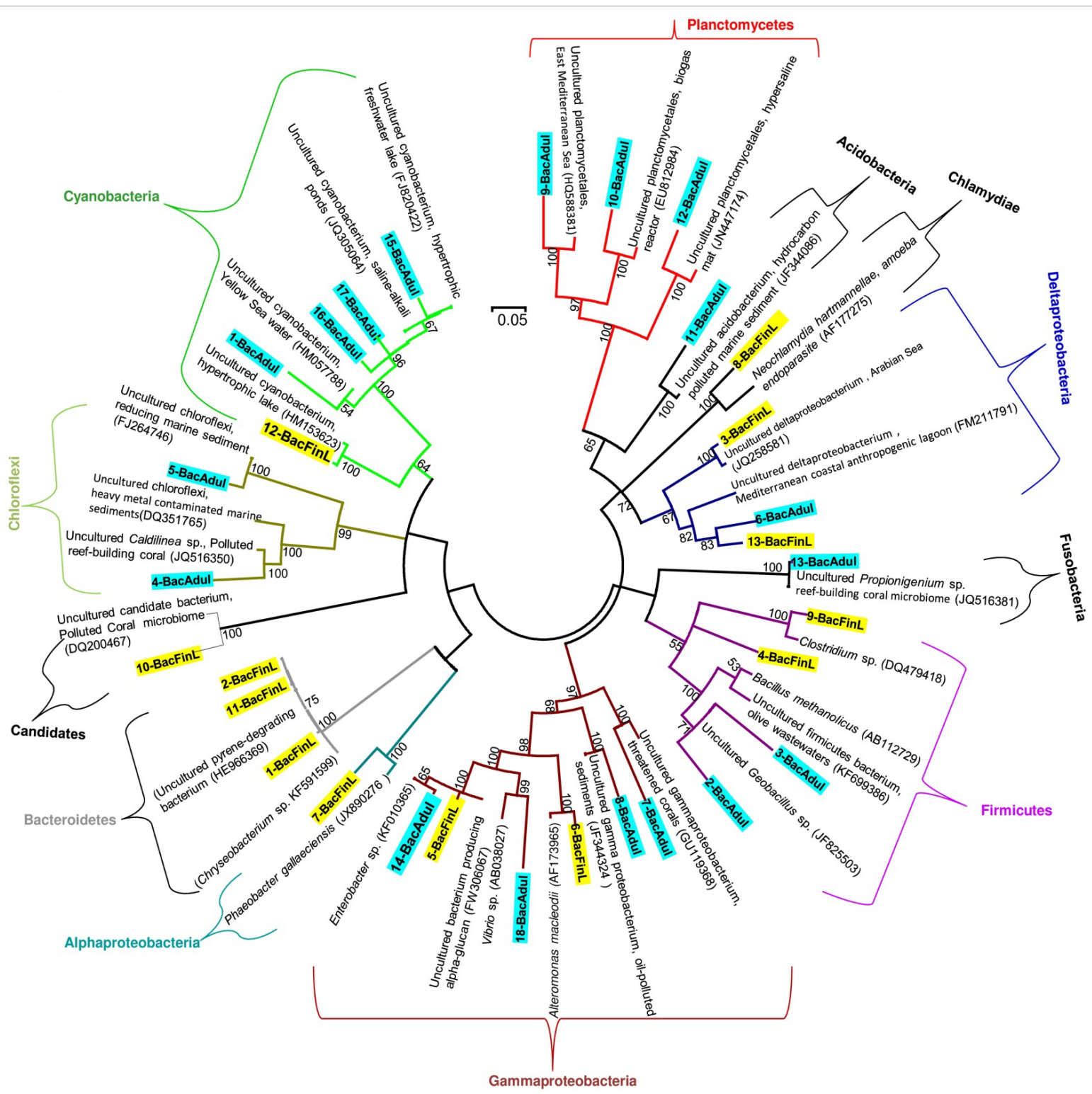

Figure 3: A consensus phylogenetic tree based on 16S rRNA gene sequences of current bacterial phylotypes in adult and fingerling guts; beside their corresponding sequences from database. Bootstrap values, more than $50 \%$, of compared algorithms, are indicated at the branch roots. The bar represents 0.05 changes per nucleotide. Accession numbers of database extracted sequences are in brackets.

and rooted with the genera, Vibrio and Enterobacter, beside uncultured gammaproteobacteria. The phylotypes 6-BacAdul, 3-BacFinL and 13-BacFinL formed phylogenetic clades with uncultured deltaproteobacteria. Studies of gut bacterial communities of fish from different genera, trophic levels and habitats have revealed that most of fish gut bacteria are from proteobacterial taxa $[10,36]$. The gut contents of adults and fingerlings contained firmicutes-like phylotypes. The phylotypes, 2- and 3-BacAdul, were linked with uncultured Geobacillus sp., while phylotypes, 4- and 9-BacFinL were rooted with Clostridium sp. (Figure 3). On the other hand, adult gut contents were characterized by harboring uncultured planctomycetales-, chloroflexi-, acidobacteriaand fusobacteria-like phylotypes.

The gut contents of fingerlings were characterized by the dominance of bacteroidetes-like phylotypes, which were rooted with the genus Chryseobacterium and uncultured bacteroidete (Figure 3). Other phylotypes, 7-BacFinl, 8-BacFinL and 10-BacFinL were located in the clusters of alphaproteobacteria, chlamydiae, and uncultured candidate bacteria, respectively, taxa, which were not recorded in the gut contents of adults. Recent sequence-based approaches have shown that fish gut microbial communities much more closely resemble to those of mammals than environmental microbial communities [36], especially in the prevalence of proteobacteria, firmicutes and bacteroidetes [13]. These findings may indicate that fishes, like other vertebrates, harbor specialized gastrointestinal communities.

\section{First record of thaumarchaeote-like phylotypes in the fish gut contents}

The composition of archaeal 16S rRNA gene pool of adult gut contents was characterized by the occurrence of 6 phylotypes, which were distributed in the cluster of thaumarchaeota (Figure 4). The phylotypes 8-, 9-ArcAdul; and 5- and 15-ArcAdul formed monophyletic clades, while the phylotype 14-ArcAdul showed a 
Citation: Elsaied HE, Taleb HTA, Wassel MA, Rashed MAS (2016) Composition of Eukaryotic and Prokaryotic Rrna Gene Phylotypes uin Guts of Adults and Fingerlings of Mugil cephalus, Inhabiting an Egyptian Mediterranean Estuary. J Phylogen Evolution Biol 4: 164. doi:10.4172/23299002.1000164

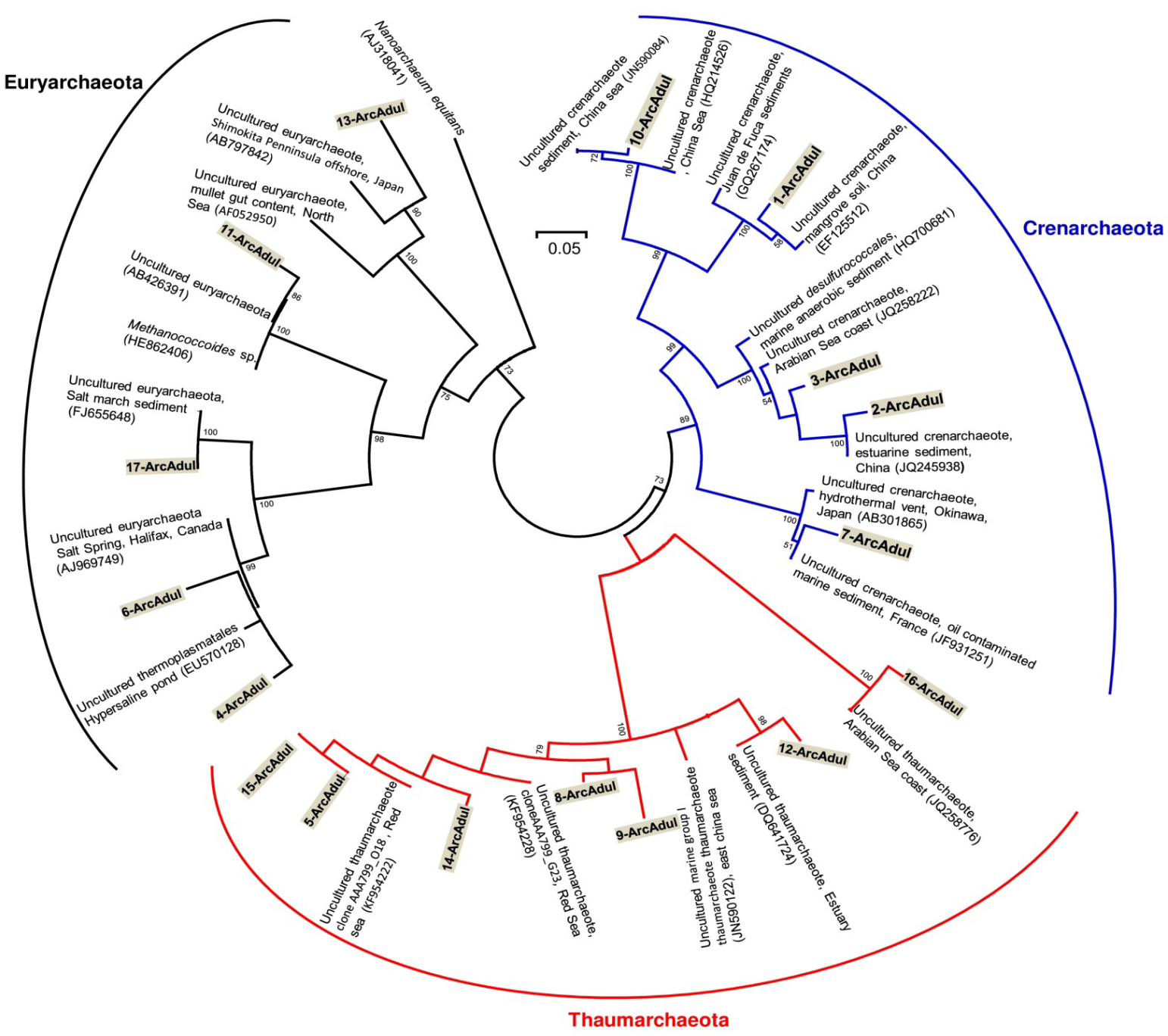

Figure 4: A consensus phylogenetic tree based on 16S rRNA gene sequences of current archaeal phylotypes in adult guts; beside their corresponding sequences from database. Bootstrap values, more than $50 \%$, of compared algorithms, are indicated at the branch roots. The bar represents 0.05 changes per nucleotide. Accession numbers of database extracted sequences are in brackets.

single phylogenetic lineage in the branch of thaumarchaeota (Figure 4). Thaumarchaeota or thaumarchaea are a deep-branching phylum of archaea, proposed in 2008 [37]. There are about 6405 nucleotide sequences have been recorded for marine uncultured thaumarchaeota $16 \mathrm{~S}$ rRNA gene, a limited sequence records, compared with other well-known archaeal phyla. The phylogeny and ecological role of thaumarchaeota are still incompletely understood, with respect of ammonia oxidation. The current thaumarchaeota-like phylotypes supported the concept that this phylum is widely distributed, not only in marine sediment, but also in fish guts [38], implicating a biological contribution in fish metabolism.

Other archaeal rRNA gene phylotypes were located in the clusters of uncultured euryarchaeota and crenarchaeota. Only a single euryarchaeota-like phylotype has been recorded in the gut of $M$. cephalus, from the North Sea, and showed an average nucleotide identity percentage, $70 \%$, with the current euryarchaeota-like phylotypes (Figure 4) [39]. This observation may indicate that the guts of $M$. cephalus can harbor a diverse of euryarchaeotes. Five phylotypes formed phylogenetic clades with uncultured crenarchaeotes from different marine sediments, an implication for ingestion of variable crenarchaeote-containing sediments by the fish.

\section{M. cephalus gut communities were shaped by varieties of biogeographic distant species}

The phylotypes 4-EukAdul was rooted with euryhaline B. plicatilis, while the phylotype 12-EukAdul formed monophyletic clade with freshwater B. calyciflorus (Figure 2). The phylotypes, 15-EukAdul and 18-EukAdul, were belonged to freshwater C. menegheniana and Scenedesmus sp., respectively (Figure 2). In addition, the phylotypes 19-, 20- and 21-EukAdul had marine fish origins. In the term of gut bacterial composition, the cyanobacteria-like phylotypes were located in the cluster, which included uncultured cyanobacteria from freshwater hypertrophic lake (acc.no. FJ820422) and seawater (acc.no. HM057788) (Figure 3). These observations implicate that the studied fish fed on preys, which came from different geographic habitats, and consequently, showing flexibility in the mode of feeding.

The studied fish guts harbored phylotypes, which may be considered as Lessepsian species. The phylotypes 5-, 8-, 9-, 14-, and 15-ArcAdul had nucleotide identity percentages, from $99.2 \%$ to $99.8 \%$, with those 
Citation: Elsaied HE, Taleb HTA, Wassel MA, Rashed MAS (2016) Composition of Eukaryotic and Prokaryotic Rrna Gene Phylotypes uin Guts of Adults and Fingerlings of Mugil cephalus, Inhabiting an Egyptian Mediterranean Estuary. J Phylogen Evolution Biol 4: 164. doi:10.4172/23299002.1000164

Page 8 of 9

from Red sea brine pools (Figure 4) [40]. Ashtum El-Gamil estuary is located at $7 \mathrm{Km}$ west of the Mediterranean gate of Suez Canal, which connects Red Sea with Mediterranean, and may facilitate the migration of these thaumarchaeotes through water current to inhabit this estuary. However, further studies must be done to evaluate this idea.

\section{Guts of adults and fingerlings shared microbiota}

Some phylotypes from guts of both adults and fingerlings were considered belonging to the same phylogenetic taxon. The phylotypes 3-EukAdul had nucleotide identity percentage of $99.22 \%$ with 3-EukFinL and both formed monophyletic clade within the phylogenetic branch of rotifers (Figure 2). The same case was observed with the phylotypes 12-EukAdul, 2-EukFinL and 4-EukFinL, which linked together with $B$. calyciflorus in a single phylogenetic cluster. Moreover, the cluster, which harbored $A$. procerus showed the close phylogenetic relationship among the phylotypes 9-, 10-, 11-EukAdul and 6-EukFinL. These observations may indicate that both of adults and fingerlings prefer these prey species for their growth and health.

On the other hand, single species of deltaproteobacteria was expected to be existed in both of adult and fingerling gut contents, representing by the phylotypes 6-BacAdul and 13-BacFinL (Figure 3). Deltaproteobacteria play an important role in food fermentation within guts of animals through reduction of sulfate into hydrogen sulfide gas, suggesting core microbial communities [41].

\section{Gut bacteria and health of fish}

The guts of adults and fingerlings harbored phylotypes, which were homologues to various bacteria, which may affect the health of fish. The phylotypes 14-BacAdul and 5-BacFinL were homologues to Enterobacter sp. (Figure 3), which infects the kidneys of $M$. cephalus, leading to mortality [42]. On the other hand, the phylotype 9-BacFinL showed nucleotide identity percentage, $98.23 \%$, with Clostridium in the same phylogenetic clade (Figure 3). A species of Clostridium was isolated from the gut of mullet by [43] and was found to be responsible for degradation of alginate in the intestinal tract of the fish. The phylotype 8-BacFinL formed monophyletic clade with the Neochlamydia hartmannellae, an endoparasite of amoeba [44].

Current fish guts were reservoirs for water pollution-related bacteria. The phylotypes 15-BacAdul, 12-BacFinL, 4-BacAdul and 10 -BacFinL had an average nucleotide identity percentage, 98.3\%, with uncultured cyanobacteria (acc. nos. FJ820422, HM153623), uncultured chloroflexi (acc. nos.JQ516350, DQ351765) and uncultured candidate bacterium (acc.no.DQ200467) respectively, (Figure 3), which came from hypertrophic, hydrocarbon and heavy metals polluted habitats [45-47]. In the phylogenetic branch of bacteroidetes, the phylotypes 1-, 2- and 11-BacFinL had an average nucleotide identity percentage, $99.89 \%$, with uncultured pyrene-degrading bacterium from heavy hydrocarbon contaminated soil [48]. The phylotypes 8-BacAdul and 11-BacAdul were related to uncultured gammaproteobacterium and acidobacterium, respectively, from oil hydrocarbon polluted environments [49]. Ashtum El-Gamil estuary undergoes pollution with oil wastes of dredging tools, which used for continuous cleaning of the estuary, beside sewage water, which comes from some of the lake drains through tide and hide between the lake and sea. These anthropogenic activities may favor the eutrophication and blooming of pollution-related bacteria, which may be taken by the fish through water current.

\section{Conclusion}

This study presented a complete profile for phylogenetic diversity of gut microbiome of two life stages, adult and fingerlings, of M. cephalus, at a Mediterranean estuary. The study was based on culture-independent ssrRNA gene analyses. The study recorded 21 phylotypes of eukaryote $18 \mathrm{~S}$ rRNA gene, 18 phylotypes of bacterial $16 \mathrm{~S}$ rRNA gene and 17 archaeal $16 \mathrm{~S}$ rRNA gene phylotypes, in the guts of adults. The guts of fingerlings harbored 7 and 13 eukaryote 18S rRNA gene phylotypes and bacterial 16S rRNA gene phylotypes, respectively. Phylogenetic analyses uncover zooplankton-like phylotypes as a dominant eukaryote fraction in the guts of both adults and fingerlings. Proteobacteria and cyanobacteria-like $16 \mathrm{~S}$ rRNA gene phylotypes were dominated in the guts of adults. The bacteroidetes-like phylotypes characterized the guts of fingerlings. The guts of adults harboured archaeal-like phylotypes in the branch of thaumarchaeota, a phenomenon that has not been recorded before and gave us an evidence for the dissemination of this phylum in the guts of fishes. The studied fish guts may considered as a reservoir for geographic distant species, including Lessepsian species, with respect to some core gut microbiota. Also, the pollution in the estuary could shape a fraction of the studied fish gut microbiota. Future studies are needed to understand the biological significance of all recorded gut microbiota, especially those of belonging to thaumarchaeotes.

\section{Acknowledgement}

We thank all technical and administrative stuff at National Institute of Oceanography and fisheries, Egypt, for providing facilities for sampling and laboratory works. This study was funded by Grant-in-Aid for scientific research, project number, 5592, from Science and Technological Development Fund (STDF), Egypt.

\section{References}

1. Round JL, Mazmanian SK (2009) The gut microbiota shapes intestinal immune responses during health and disease. Nat Rev Immunol 9: 313-323.

2. Asuquo P, Eyo V, Ikechukwu C (2015) Feeding ecology, length-weight relationship and condition factor of Mugil cephalus (Pisces: Mugilidae; Linnaeus, 1758) from cross river estuary, Nigeria. Eur Acad Res II: 1527615294.

3. Llewellyn M, McGinnity P, Dionne M, Letourneau J, Thonier F, et al. (2015) The biogeography of the atlantic salmon (Salmo salar) gut microbiome. The ISME Journal.

4. Moriarty DJ (1976) Quantitative studies on bacteria and algae in the food of the mullet Mugil cephalus L. and the prawn Metapenaeus bennettae (Racek \& Dall). Ecology 22: 131-143

5. Rao RK, Babu KR (2013) Studies on food and feeding habits of Mugil cephalus (LINNAEUS, 1758) East coast off Andhra Pradesh, India. Canadian J pure Appl Sci 7: 2499-2504.

6. Rueda S (2002) Stomach content analysis of Mugil cephalus and Mugil curema (Mugiliformes: Mugilidae) with emphasis on diatoms in the Tamiahua lagoon, México. Rev Biol Trop 50: 245-252.

7. Kumary K (2015) Food and feeding habits of Mugil cephalus of Kayamkulam estuary, Kerala. Int J Aqua 5: 1-3.

8. Sabatés A, Zaragoza N, Raya V (2015) Distribution and feeding dynamics of larval red mullet (Mullus barbatus) in the NW Mediterranean: the important role of cladocera. J plankton res 37: 820-833.

9. Ghosh S, Ring $\varnothing$ E, Selvam A, Rahiman K, Sathyan N, et al. (2014) Gut associated lactic acid bacteria isolated from the estuarine fish Mugil cephalus: Molecular diversity and antibacterial activities against pathogens. Int J Aqu 4 : 1-11.

10. Nayak SK (2010) Role of gastrointestinal microbiota in fish. Aquaculture Research 41: 1553-1573.

11. Fidopiastis P, Bezdek D, Horn A, Kandel J (2006) Characterizing the resident, fermentative microbial consortium in the hindgut of the temperate-zone herbivorous fish, Hermosilla azurea (Teleostei: Kyphosidae). Mar Biol 148: 631-642.

12. Wu S, Wang G, Angert E, Wang W, Li W, et al. (2012) Composition, diversity, and origin of the bacterial community in grass carp intestine. PLOS One 7 : e30440. 
Citation: Elsaied HE, Taleb HTA, Wassel MA, Rashed MAS (2016) Composition of Eukaryotic and Prokaryotic Rrna Gene Phylotypes uin Guts of Adults and Fingerlings of Mugil cephalus, Inhabiting an Egyptian Mediterranean Estuary. J Phylogen Evolution Biol 4: 164. doi:10.4172/23299002.1000164

Page 9 of 9

13. Ye L, Amberg J, Chapman D, Gaikowski M, Liu W (2014) Fish gut microbiota analysis differentiates physiology and behavior of invasive Asian carp and indigenous American fish. The ISME Journal 8: 541-551.

14. Kim DH, Brunt J, Austin B (2007) Microbial diversity of intestinal contents and mucus in rainbow trout (Oncorhynchus mykiss). J Appl Microbiol 102: 16541664.

15. Namba A, Mano N, Hirose H (2007) Phylogenetic analysis of intestinal bacteria and their adhesive capability in relation to the intestinal mucus of carp. J Appl Microbiol 102: 1307-1317.

16. Wu S, Gao T, Zheng Y, Wang W, Cheng Y, et al. (2010) Microbial diversity of intestinal contents and mucus in yellow catfish (Pelteobagrus fulvidraco). Aquaculture 303: 1-7

17. Elsaied H, Kimura H, Naganuma T (2002) Molecular characterization and endosymbiotic localization of the gene encoding D-ribulose 1,5-bisphosphate carboxylase-oxygenase (RuBisCO) form II in the deep-sea vestimentiferan trophosome. Microbiology 148: 1947-1957.

18. Lepere C, Demura M, Kawachi M, Romac S, Probert I, et al. (2011) Wholegenome amplification (WGA) of marine photosynthetic eukaryote populations. FEMS Microbiol Ecol 76: 513-523.

19. Lane DJ, Pace B, Olsen GJ, Stahl DA, Sogin ML, et al. (1985) Rapid determination of $16 \mathrm{~S}$ ribosomal sequences for phylogenetic analyses. Proc Natl Acad Sci USA 82: 6955-6959.

20. DeLong E, Pace N (2001) Environmental diversity of bacteria and archaea Syst Biol 50: 470-478.

21. Schloss PD, Westcott SL, Ryabin T, Hall JR, Hartmann M, et al. (2009) Introducing Mothur: open source, platform-independent, community-supported software for describing and comparing microbial communities. Appl Environ Microbiol 75: 7537-7541.

22. Sarasquete C, Ortiz-Delgado J, Martos-Sitcha J, Heras V, Yúfera M, et al. (2014) Ontogeny and functional histochemistry of the digestive and visual systems and other organs during the larval development of the thick-lipped grey mullet, Chelon labrosus. Scientia Marina 78: 473-491.

23. Suzuki M, Giovannoni S (1996) Bias caused by template annealing in the amplification of mixtures of $16 \mathrm{~S}$ rRNA genes by PCR. Appl Environ Microbio 62: $625-630$.

24. Jamabo N, Maduako N (2015) Food and feeding habits of Mugil cephalus (Linnaeus, 1758) in Elechi Creek, Niger delta, Nigeria. Int J Fish Aqua 7: 25-29.

25. Hamid A, Sakata T, Kakimoto D (1977) Microflora in the alimentary tract of gray mullet III: Study on the characteristics of the intestinal microflora in different conditions. Memoirs of Faculty of Fisheries Kagoshima University, 26: 79-87.

26. Nagvenkar GS, Nagvenkar SS, Rivonker CU, Sangodkar UM (2006) Microbia diversity and enzyme production in mullet Mugil cephalus L. (Pisces) along Goa, west coast of India. Indian J Mar Sci 35: 36-42.

27. Givens C, Ransom B, Bano N, Hollibaugh J (2015) Comparison of the gut microbiomes of 12 bony fish and 3 shark species. Mar Ecol Prog Ser 518: 209-223.

28. Aguinaldo AM, Turbeville JM, Linford LS, Rivera MC, Garey JR, et al. (1997) Evidence for a clade of nematodes, arthropods and other moulting animals. Nature 387: 489-493

29. Golombek A, Tobergte S, Nesnidal MP, Purschke G, Struck TH (2013) Mitochondrial genomes to the rescue - Diurodrilidae in the myzostomid trap. Mol Phylo Evol 68: 312-326.

30. Malekzadeh-Viayeh R, Pak-Tarmani R, Rostamkhani N, Fontaneto D (2014) Diversity of the rotifer Brachionus plicatilis species complex (Rotifera: Monogononta) in Iran through integrative taxonomy. Zoological Journal of the Linnean Society 170: 233-244.

31. Bishop J, Miglarese J (1978) Carnivorous feeding in adult stripped mullet Copeia 705-709.

32. Blanco S, Romo S, Villena M, Marti'nez S (2003) Fish communities and food web interactions in some shallow Mediterranean lakes. Hydrobiologia 506: 473-480.

33. Alverson A, Jansen R, Theriot E (2007) Bridging the Rubicon: Phylogenetic analysis reveals repeated colonizations of marine and fresh waters by thalassiosiroid diatoms. Mol Phylo Evol 45: 193-210.
34. Beszteri B, John U, Medlin L (2007) An assessment of cryptic genetic diversity within the Cyclotella meneghiniana species complex (Bacillariophyta) based on nuclear and plastid genes, and amplified fragment length polymorphisms. Eur J Phycol 42: 47-60.

35. Hegewald EH, Eberhard H (1997) Taxonomy and phylogeny of Scenedesmus The Korean Journal of Phycology 12: 235-246.

36. Sullam K, Essinger S, Lozupone C, O'Connor M, Rosen G, et al. (2012 Environmental and ecological factors that shape the gut bacterial communities of fish: a meta-analysis. Mol Ecol 21: 3363-3378.

37. Brochier-Armanet C, Boussau B, Gribaldo S, Forterre P (2008) Mesophilic crenarchaeota: Proposal for a third archaeal phylum, the Thaumarchaeota. Nat Rev Microbiol 6: 245-252.

38. Pester M, Schleper C, Wagner M (2011) The Thaumarchaeota: an emerging view of their phylogeny and Ecophysiology. Curr Opinion Microbiol 14: 300306.

39. Van DER Maarel M, Artz R, Haanstra R, Forney L (1998) Association of marine archaea with the digestive tracts of two marine fish species. Appl Environ Microbiol 64: 2894-2898

40. Ngugi D, Blom J, Alam I, Rashid M, Ba-Alawi W, Zhang G, Hikmawan T, et al. (2014) Comparative genomics reveals adaptations of a halotoleran thaumarchaeon in the interfaces of brine pools in the Red Sea. The ISME Journal 9: 396-411.

41. Mclnerney MJ, Struchtemeyer CG, Sieber J, Mouttaki H, Stams AJ, et al. (2008) Physiology, ecology, phylogeny, and genomics of microorganisms capable of syntrophic metabolism. Ann N Y Acad Sci 1125: 58-72.

42. Sekar VT, Santiago TC, Vijayan KK, Alavandi SV, Raj VS, et al. (2008) Involvement of Enterobacter cloacae in the mortality of the fish, Mugil cephalus. Lett Appl Microbiol 46: 667-672.

43. Mountfort DO, Rainey FA, Burghardt J, Stackebrandt E (1994) Clostridium grantii sp. nov., a new obligately anaerobic alginolytic bacterium isolated from mullet gut. Arch Microbiol 162: 173-179.

44. Horn M, Wagner M, Müller KD, Schmid EN, Fritsche TR, et al. (2000) Neochlamydia hartmannellae gen. nov., sp. nov. (Parachlamydiaceae), an endoparasite of the amoeba Hartmannella vermiformis. Microbiology 146 1231-1239.

45. Gillan DC, Pernet P (2007) Adherent bacteria in heavy metal contaminated marine sediments. Biofouling 23: 1-13.

46. Kimes NE, JohnsonWR, Torralba M, Nelson KE, Weil E, et al. (2013) The Montastraea faveolata microbiome: ecological and temporal influences on a Caribbean reef-building coral in decline. Environ Microbiol 15: 2082-2094.

47. Li H, Xing P, Chen M, Bian Y, Wu QL (2011) Short-term bacterial community composition dynamics in response to accumulation and breakdown of microcystis blooms. Water Res 45: 1702-1710.

48. Peng J, Zhang Y, Su J, Qiu Q, Jia Z, et al (2013) Bacterial communitie predominant in the degradation of (13) C4-4,5,9,10-pyrene during composting Bioresour Technol 143: 608-614.

49. Acosta-Gonzalez A, Rossello-Mora R, Marques S (2013) Characterization of the anaerobic microbial community in oil-polluted subtidal sediments: aromatic biodegradation potential after the Prestige oil spill. Environ Microbiol 15: 77-92. 